MILAN JAIĆ*, TANJA PALIJA

University of Belgrade, Faculty of Forestry, Department of TMP

- Technology, Management and Design of Wood and Wood

Based Produc, Belgrade, Serbia
Scientific paper

ISSN 0351-9465, E-ISSN 2466-2585

UDC:620.191.5

doi:10.5937/ZasMat1504457J

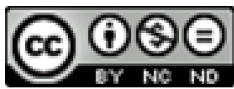

Zastita Materijala 56 (4)

457 - 462 (2015)

\title{
High gloss finish: the impact of surface roughness on gloss
}

\begin{abstract}
The cured finishes always contain certain irregularities that result from the technique and conditions of application. For this reason, in order to achieve smooth high gloss finished surfaces, it is necessary to polish ("rub-out") surfaces coated with high gloss finish. Rubbing means sanding the finished surfaces with very fine abrasive grits. In this paper we explored how each phase of the polishing process affect the surface roughness and the gloss of coated surface. The surface roughness was expressed by the parameters: $R_{a}, R_{z}$ and $R_{t}$, and the gloss was determined by reflectometer (measurement angles $20^{\circ}$ and $60^{\circ}$ ). The results showed that through the stages of polishing, surface roughness decreased, while gloss of finished surface increased. The high value of the coefficient of determination $\left(R^{2}=0,984\right)$ indicated the linear dependence between the roughness parameter $R_{a}$ and gloss of finished surface (at measuring angle of $60^{\circ}$ ). The comparison of gloss results obtained by two measuring angles, confirmed the need for using the angle of $20^{\circ}$ when determining the gloss of high gloss surfaces, since universal angle of $60^{\circ}$ did not provided insight to small differences in the gloss that appeared as a result of polishing.
\end{abstract}

Keywords: coating, polishing, surface roughness, high gloss.

\section{INTRODUCTION}

With adequate surface finishing it is possible to answer to different customers' demands in terms of aesthetic appearance of wood products and thus increase the value of the product itself. One of the trends in surface finishing of wood is lacquering in high gloss. The gloss of coated surfaces depends on the characteristics of coatings (color and refractive index of coating) and surface roughness of the film coating [1]. In pigmented coating pigment particle size influences the degree of gloss [2]. In addition, the gloss of coated surfaces can be influenced by the method of preparation of the substrate and the previous layer of coating [1].

The roughness in the surface layer of the film coating is caused by the volume reduction of the coating during drying and due to the presence of submicron particles in the coating formulation (micro-roughness). On the other hand, coating application procedures (brush marks etc.), as well

*Corresponding author: Milan Jaić

E-mail: milan.jaic@sfb.bg.ac.rs

Paper received: 24. 06. 2015.

Paper accepted: 23. 08. 2015.

Paper is available on the website: www.idk.org.rs/casopis as flow induced by surface tension gradients, contribute to the roughness of the film coating (macro-roughness) [1]. In addition, the conditions of application and curing of coatings can never be absolutely controlled and free from impurities that may impair smoothness of the film coating [3].

The use of coating with addition of additives for high gloss appearance is not a sufficient factor to achieve high glossy coated surfaces. Consequently, high gloss coating technology is more demanding compared to conventional coating technologies (matt glow etc.). The unevenness in the film coating are most often removed by the polishing process. Polishing implicate the degradation of film coating by sanding procedure [4]. Sanding (abrasive) grains that are used in the process of polishing are mini blades that are "scratching" the surface of the film coating and thus removing traces of previous operations. To obtain a mirror-flat high gloss finish it is necessary to gradually decrease the roughness of coated surface by progressively reducing the size of the abrasive grains in the process of polishing.

The objective of this research was to examine how process of polishing affects the surface roughness and gloss of coated surfaces of wood based boards. 


\section{MATERIALS AND METHODS}

In this research we used samples of medium density fiberboard (mdf) coated with primer foil which were coated with one layer of white polyester $(P E)$ coating and one layer of white polyurethane (PU) coating. Totally, 5 samples of dimensions 300 $\times 300 \times 20 \mathrm{~mm}$ were used. The samples were prepared by sanding on the sanding machine with three units (manufacturer Biesse, Italy, model VIET T1T33), of which the first and third unit had segmental compression beam and narrow sanding belt, while the second unit had contact beam and wide sanding belt. The sanding direction was perpendicular to the direction of conveyor belt movement on the first and third sanding unit, and parallel to conveyor belt on the second sanding unit. Primer foil was sanded on this machine using sanding belt with grit P80 which was placed on the first sanding unit.

After preparing the substrate, one layer of twocomponent (2K) PE sealer was applied by airmix spraying. The components of coating: base (ICA HS330102), hardener (ICA SC480430) and accelerator (ICA HS390160) were mixed in a ratio of 100: 2: 2, respectively. For the mixing of components two-component system was used, wherein $50 \%$ of the base and hardener comprised a single component, and the rest of the base and accelerator comprise the second component. Both components were diluted prior to application with $15 \%$ of acetone. Spraying pressure was set to 5 $6 \mathrm{bar}$, and the nozzle tip diameter was $1,3 \mathrm{~mm}$. The average application rate based on five measurements was about $340 \mathrm{~g} / \mathrm{m}^{2}$.

After $24 \mathrm{~h}$ of drying of $\mathrm{PE}$ coating samples were sanded on the above mentioned sanding machine with activation of all three sanding units and the use the following grits of sanding papers: P320, P400 and P600.

Sanded samples were coated with one layer of top $2 \mathrm{~K}$ PU coating by air spraying. Base component (POLISTUC LT 008) and hardener (POLISTUC CT325) were mixed in ratio of 1:1 and diluted by addition of $20 \%$ of thinner (POLISTUC DL043). The spraying pressure was set to $5-6$ bar, and the nozzle tip diameter was $1,4 \mathrm{~mm}$. The average application rate based on five measurements was about $70 \mathrm{~g} / \mathrm{m}^{2}$.

Coating of the sample was performed in the overpressure chamber under controlled conditions of the working environment $\left(\mathrm{t}=23,5^{\circ} \mathrm{C}\right.$ and $\varphi=$ $28 \%$ ), while the parameters of the environment were samples were drying were a little milder $(t=$ $20^{\circ} \mathrm{C}$ and $\varphi=33 \%$ ).

After drying of $\mathrm{PU}$ coating samples were sanded on the above mentioned sanding machine with activation of the units for transverse sanding and using the following grit of sanding papers: P1000, P1200 and P1500.

Sanding speed in all phases of surface treatment of samples was $20 \mathrm{~m} / \mathrm{s} ; 8 \mathrm{~m} / \mathrm{s}$ and $16 \mathrm{~m} / \mathrm{s}$ for I, II and III sanding unit, respectively, while the speed of conveyer belt was $8 \mathrm{~m} / \mathrm{min}$.

Polishing of the samples was performed on a machine equipped with 6 rotating polishing rollers, which were mounted in pairs on horizontally rotating spindles (VIETMAC), Figure 1. During the working time polishing rollers rotated around a central vertical axis, as well. All samples were passed through the machine two times at a rotation speed of polished rolls of $17 \mathrm{rpm}$ and the conveyor belt speed of $2 \mathrm{~m} / \mathrm{min}$.

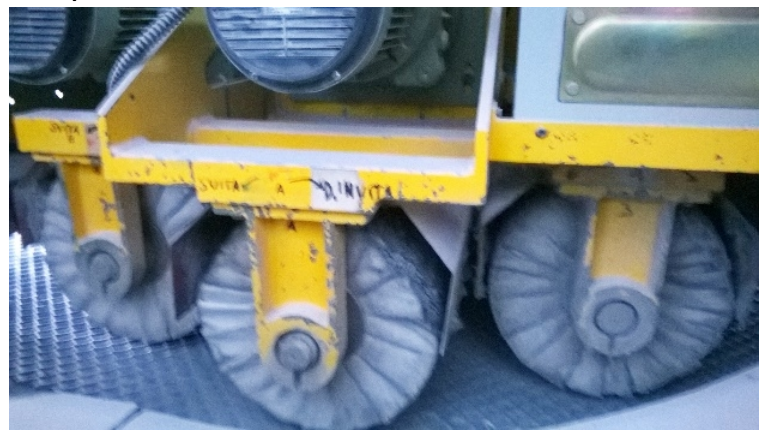

Figure 1 - Polishing rollers rotating around horizontal and central vertical axe in the polishing machine

After automated polishing the next stage of polishing of samples was done on the hand operated machine equipped with a polishing disc (manufacturer Arnaboldi ALBERTO SNC, Italz, model ETGALU), Figure 2. In order to gradually reduce the roughness of the previous stages of processing manual-polishing was carried out in two stages using two polish-pastes: coarse (3M тм Perfect-It TM III Fast Cut Plus Compound (50417)) and fine (3M TM Perfect-it TM III Extra Fine Compound (80349)). According to the recommendation of the producer of polishing pastes for each polishing paste appropriate polishing disk pad with adequate strength and texture was used.

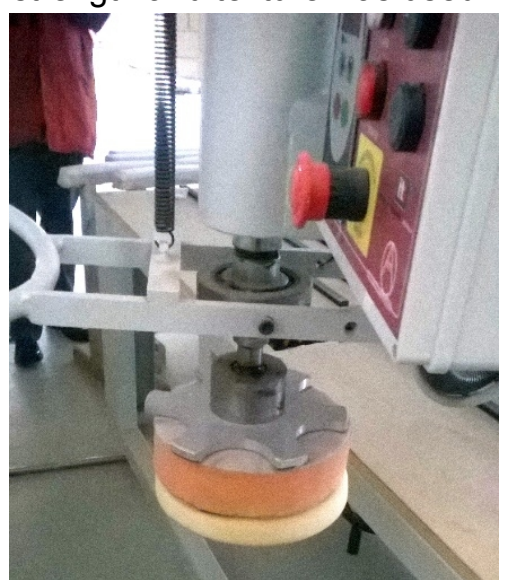

Figure 2 - Polishing disk on the hand-operated polishing machine 
The measurement of surface roughness was carried out by stylus contact tester (manufacturer Beijing TIME High Technology Ltd., model TimeSurf TR200), Figure 3. The diameter of the diamond stylus tip i $2 \mu \mathrm{m}$, and the stylus was pressed on the surface by the force of $4 \mathrm{mN}$. The direction of the measurement was chosen in a way that the highest irregularities that arise as result of processing was included in measurement.

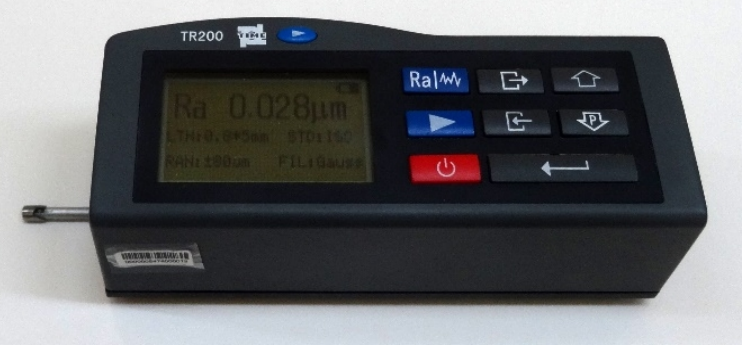

Figure 3 - Determination of surface roughness of coated surface using contact stylus surface roughness tester

For the purpose of the precise determination of the geometric state of the substrate surface roughness was evaluated based on three amplitude parameters: $R_{a}, R_{z}$ and $R_{t}$ according to the following equations [5]:

$$
R_{a}=\frac{1}{n} \sum_{i=1}^{n}\left|y_{i}\right|
$$

where $y_{i}$ is the ordinate of individual points of effective profile from the mean line within the sampling length and $n$ is total number of measurement points of effective profile, within the sampling length;

$$
R_{z}=Z_{p}+Z_{m}
$$

where $Z_{p}$ is the distance between the highest point (peak) and the mean line within the sampling length and $Z_{m}$ is the distance between the lowest point (valley) and the mean line within sampling length;

$$
R_{t}=Z_{p}+Z_{m},
$$

where $Z_{p}$ is the distance between the highest point (peak) and the mean line within the evaluation length and $Z_{m}$ is the distance between the lowest point (valley) and the mean line within the evaluation length.

Based on the test measurements and recommendations of standard [6] the sampling length of $0,8 \mathrm{~mm}$ was chosen, and the evaluation length consisted of the five sampling length. Filtering of results was performed by Gaussian filter.

The roughness was determined after sanding of samples coated with $\mathrm{PE}$ and $\mathrm{PU}$ coating; automated-polishing and manual-polishing with appropriate polishing pastes. For each sample roughness parameters were determined at four positions after each stage of processing.

The dry film thickness of the coating was determined without destruction of the coating by ultrasonic gauge (manufacturer DeFelsko, USA, model PosiTector 200 Series), according to standard [7], Figure 4. The result was presented as the mean value based on 10 measurements on each sample. The dry film thickness of the coating was determined for each coating layer, as well as the total thickness of both layers of the coating. In addition, the loss of the dry film thickness coating after inter-sanding between coatings was calculated.

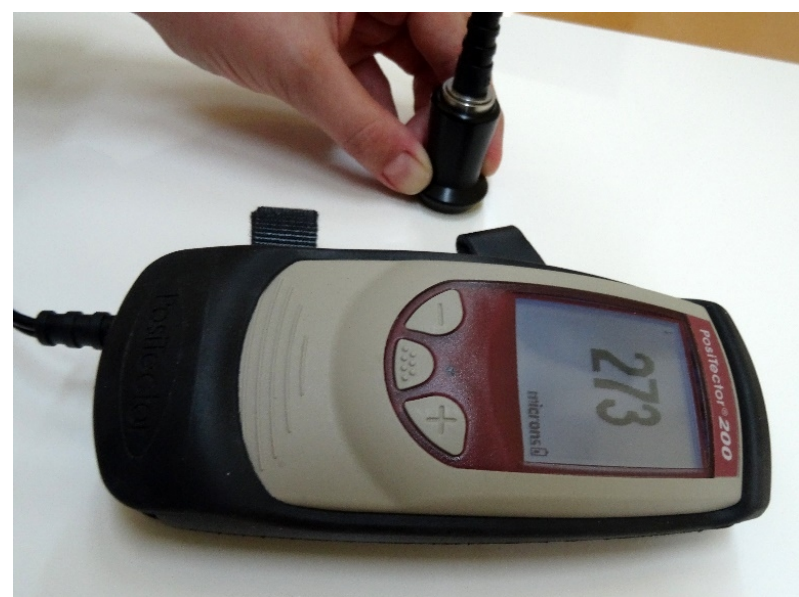

Figure 4 - Determination of dry film thickness of coating by ultrasonic gauge

The gloss of coated samples was determined by the method of reflectometer (manufacturer RHOPOINT Instruments Ltd., UK, model NovoGloss Trio), Figure 5.

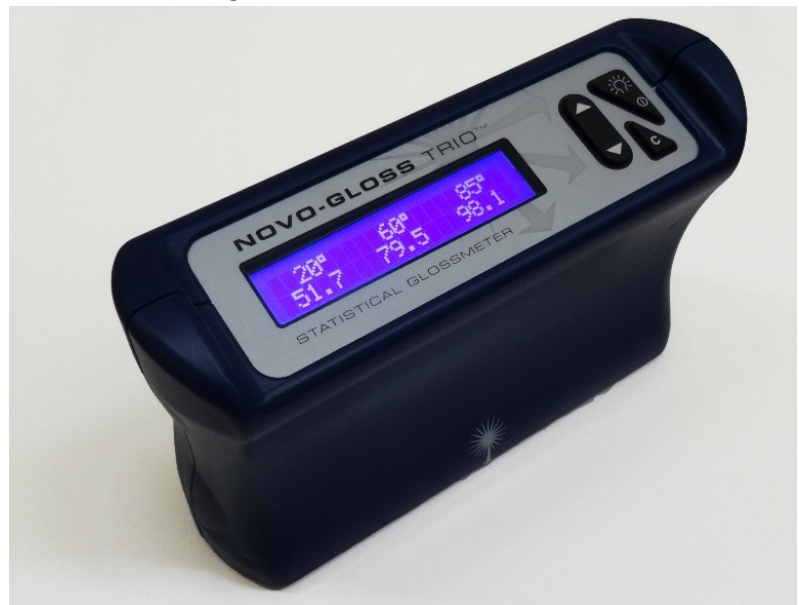

Figure 5 - Determination of the gloss of coated surface

The measurement of gloss was carried out according to standard [8], using measurement geometries of $60^{\circ}$ and $20^{\circ}$. The measurement 
geometry of $60^{\circ}$ is considered universal geometry for determining the gloss of coated surfaces, while the geometry of $20^{\circ}$ is recommended for a more accurate determination of gloss of surface that have values of gloss above $70 \mathrm{GU}$, when measured with the geometry of $60^{\circ}$. The values of gloss was presented as average value of 10 measurements on each sample. The measurement of gloss was done after application and drying of the top PU coating and after every stage of polishing: automated-polishing and the first and second stage of manual-polishing.

\section{RESULTS AND DISCUSSION}

Table 1 shows the dry film thickness of the individual layers of the coating, the total thickness of the coating, as well as the loss in the thickness of the coating during intermediate sanding between layers.

Table 2 shows the surface roughness of coated samples based on three amplitude parameters: $R_{a}$, $R_{z}$ and $R_{t}$ after application, drying and sanding of the top PU coating, and after individual stages of polishing of coated surface of samples.

Table1 - Dry film thickness of individual layers of coatings; total dry film thickness and loss of coating during inter-layer sanding

\begin{tabular}{|l|c|c|c|c|}
\hline & PE coating & $\begin{array}{c}\text { Loss of coating during } \\
\text { sanding }\end{array}$ & PU coating & $\begin{array}{c}\text { Total amount of } \\
\text { coating }\end{array}$ \\
\hline Average dry film thickness $[\mu \mathrm{m}]$ & 269 & 79 & 52 & 242 \\
\hline
\end{tabular}

Table 2 - Surface roughness parameters of coated surface after different phases of polishing

\begin{tabular}{|l|c|c|c|}
\hline & \multicolumn{2}{|c|}{ Parameters of surface roughness [ $\mu \mathrm{m}]$} \\
\hline Phase of processing & $R_{a}$ & $R_{z}$ & $R_{t}$ \\
\hline Sanding of top coating & 0,222 & 1,723 & 2,145 \\
\hline Automated-polishing & 0,070 & 0,643 & 0,972 \\
\hline Manual-polishing I stage & 0,063 & 0,564 & 0,799 \\
\hline Manual-polishing II stage & 0,057 & 0,500 & 0,834 \\
\hline
\end{tabular}

Comparing the surface roughness parameters of coated surfaces after different stages of polishing, it is evident that the highest roughness was obtained after sanding of coated samples which can be explained by larger size of the abrasive grain on sanding belts in relation to the size of abrasive grains in the formulation of polishing pastes. In addition, the processing parameters (sanding/polishing) may affect the values of roughness parameters of coated surfaces.

In terms of surface roughness of coated samples, the reduction of the observed roughness parameters with the later stages of polishing was evident. The only exception from this observation was the parameter $R_{t}$ which value is slightly higher after the second degree of manual-polishing compared to its value after the first stage of manual-polishing. Since this parameter refers to the maximum height of the peaks/valleys which may form during scratching of surface by abrasive grains, it is assumed that the higher value of this parameter in the last phase of polishing is a consequence of the different sizes of abrasive grains within a single grit of sanding paper.

The high value of the correlation coefficient $\left(R^{2}\right.$ $=0,999$ ) shows that there is a linear direct dependence between the parameters $R_{a}$ and $R_{z}$ of coated surfaces after different stages of automated and manual-polishing, figure 6 . This result indicates the uniformity of surface roughness, regarding the removal of unevenness that existed in the film coating by polishing. Lower values of the coefficient of correlation between parameters $R_{a}$ and $R_{t}\left(\mathrm{R}^{2}=\right.$ $0.641)$, and the parameter $R_{z}$ and $R_{t}\left(R^{2}=0.621\right)$ are in accordance with the assumption on the impact of various sizes of abrasive grains within single grit of the sanding paper on the roughness on coated surfaces.

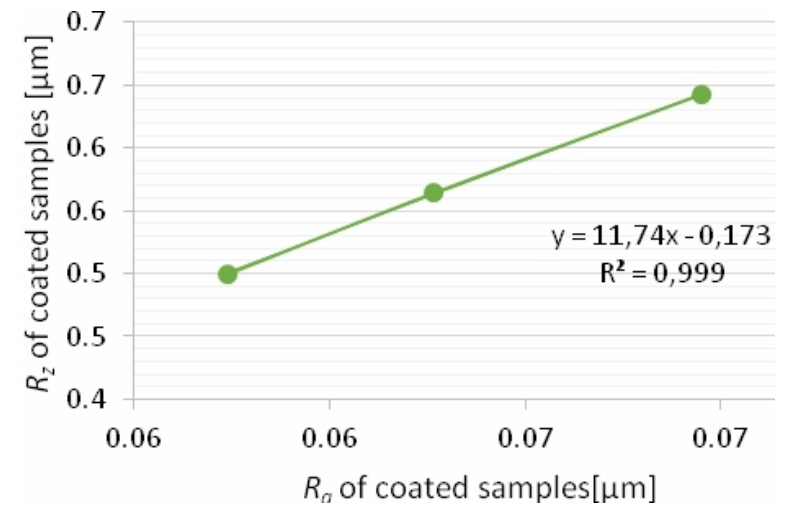

Figure 6 - Dependence between parameters $R_{a}$ and $R_{z}$ of coated samples after automated and manual polishing

Table 3 shows the values of gloss of coated surfaces at different phases of polishing measured with $60^{\circ}$ and $20^{\circ}$ geometries. 
Table 3 - Gloss of coated surface after different phases of polishing

\begin{tabular}{|l|c|c|}
\hline Gloss of coated surface & \multicolumn{2}{|c|}{ Measuring geometry } \\
\hline Phase of processing & $60^{\circ}$ & $20^{\circ}$ \\
\hline Sanding of top coating & 97,3 & 89,0 \\
\hline Automated-polishing & 82,8 & 55,3 \\
\hline Manual-polishing I stage & 91,2 & 73,6 \\
\hline Manual-polishing II stage & 95,2 & 75,4 \\
\hline
\end{tabular}

The gloss values of coated surfaces indicate that with application of high-gloss coating very high values of gloss can be achieved (97.3 GU for measuring geometry of $60^{\circ}$ ). If gloss of coated surfaces is observed based only on measurements obtained using the measuring geometry of $60^{\circ}$ it could lead to wrong conclusion that polishing of coted surface is not necessary to obtain smooth high gloss surface. However, the application of a high-gloss coating is not sufficient, since impurities that disrupt the smoothness of the film coating and gloss are always present in the working environment. This observation is confirmed by the gloss results with the measurement geometry of

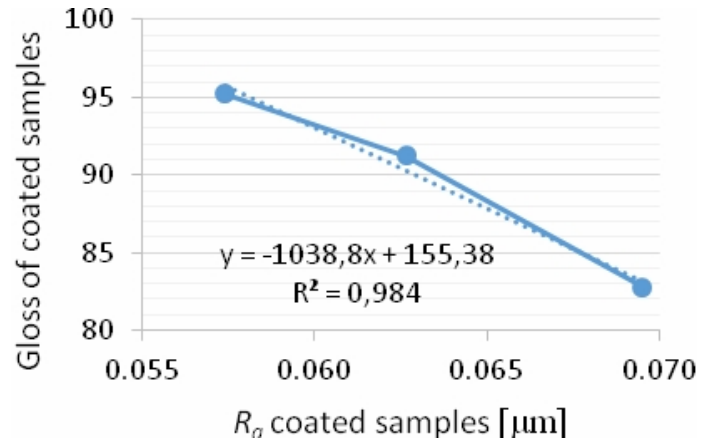

a) $20^{\circ}$, where the gloss value was significantly lower (89 GU). This result confirms the necessity of use of both measurement geometries when determining the gloss of shiny surfaces.

By automated and manual polishing the gloss of coated surface decreases in relation to gloss obtained by application of high gloss coating. This result confirms that process of polishing consist of scratching of surface with small blades, that cause increase in surface roughness. In order to obtain a smoother surface (close to the mirror like) it is necessary to remove the traces of scratching from previous stages of sanding and polishing.

The high values of the correlation coefficient $(R$ ${ }^{2}=0.984$ and $R^{2}=0.979$ ) indicate that there is a very strong direct linear dependence between gloss of coated surfaces and surface roughness expressed by parameters $R_{a}$ and $R_{z}$, respectively, when measuring geometry of $60^{\circ}$ is used, Figure 7. Slightly lower values of the correlation coefficient $\left(R^{2}=0.871\right.$ and $\left.R^{2}=0.858\right)$ was obtained between gloss of coated surfaces measured with geometry of $20^{\circ}$ and parameters $R_{a}$ and $R_{z}$ of coated surfaces, respectively, Figure 8.

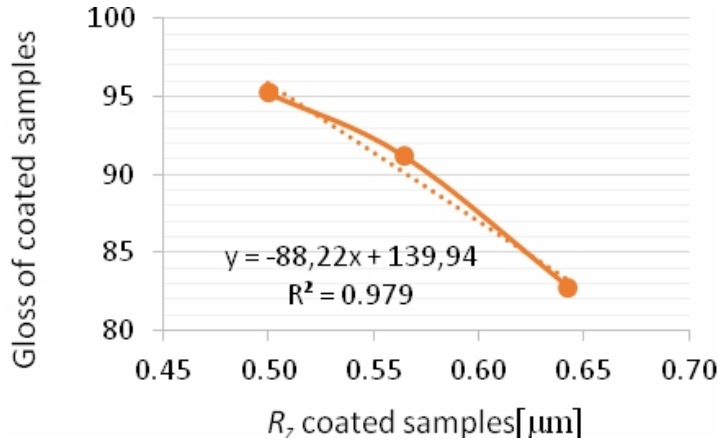

b)

Figure 7 - Relation between gloss of coated surface measured with geometry of $60^{\circ}$ and surface roughness of coated samples: a) $R_{a}$; b) $R_{\mathrm{z}}$.

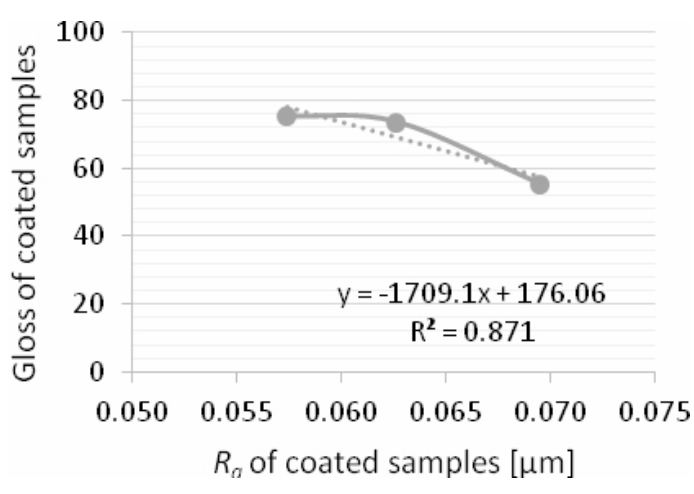

a)

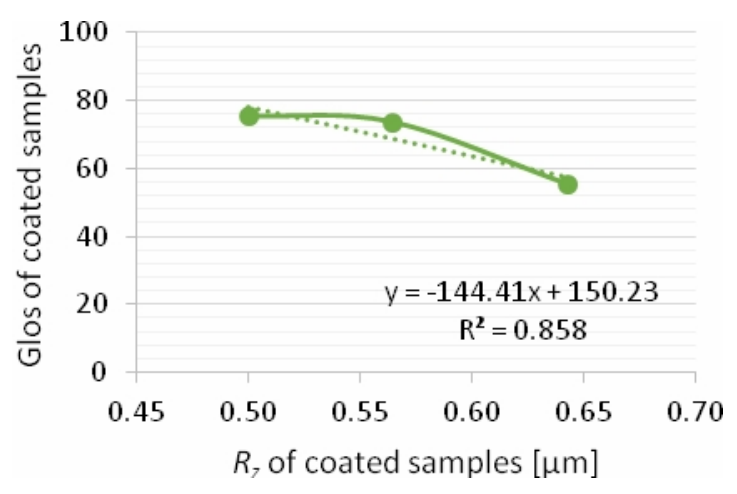

b)

Figure 8 - Relation between gloss of coated surface measured with geometry of $20^{\circ}$ and surface roughness of coated samples: a) $R_{a}$; b) $R_{z}$. 


\section{CONCLUSIONS}

Based on the results, the fallowing can be concluded:

- With a decrease in the size of the abrasive grains in polish pastes the surface roughness of the coated surface decreased while the gloss of coated samples increased.

- For characterization of the roughness of the coated surfaces roughness parameters $R_{a}$ and $R_{z}$ are recommended, based on the high value of the correlation coefficient between above parameters and the gloss of coated samples.

- For determination of the gloss of high gloss coated surfaces the use of additional measurement geometry $\left(20^{\circ}\right)$ is necessary, since measurement of gloss at an angle of $60^{\circ}$ (universal measurement geometry) does not register the small differences in film coatings that are visible to the naked eye and which disrupt evenness in film coating, and thus effect the gloss of coated surfaces.

\section{Acknowledgement}

This paper was realized as a part of the project Establishment of Wood Plantations Intended for the Afforestation of Serbia (31041) financed by the Ministry of Education, Science and Technological of the Republic of Serbia within the framework Technological development for the period 20112015.

\section{REFERENCES}

[1] B. Franco, J.A.Graystone (2009) Industrial wood coatings Theory and practice, Elsevier B.V., Amsterdam, The Netherlands, 120-121; 168-171.

[2] A. Rawle (2002) The importance of particle sizing to the coatings industry Part 1: Particle size measurement, Advances in Colour Science and Technology, 5 (1), 1-12.

[3] B. Flexner (2010) Flexner on Finishing, F+W Media, Inc., Ohio, USA, 120-123.

[4] M. Jaić, R. Živanović-Trbojević (2000) Površinska obrada drveta Teorijske osnove, Tehnološki procesi. Dr Milan Jaić, Beograd, 329-340.

[5] ISO 4287 (1996) Geometrical Product Specifications (GPS) -- Surface texture: Profile method -- Terms, definitions and surface texture parameters

[6] ISO 4288 (1996) Geometrical Product Specifications (GPS) -- Surface texture: Profile method -- Rules and procedures for the assessment of surface texture

[7] ISO 2808 (2007) Paints and varnishes - Determination of film thickness

[8] ISO 2813 (2014) Paints and varnishes - Determination of gloss value at 20 degrees, 60 degrees and 85 degrees

\section{IZVOD}

\section{PREMAZI VISOKOG SJAJA: UTICAJ HRAPAVOSTI POVRŠINE NA SJAJ}

Očvrsnuo film premaza uvek sadrži određene nepravilnosti koje su posledica postupka i uslova nanošenja. Iz tog razloga u cilju postizanja visokog sjaja lakirane površine, uz primenu premaza visokog stepena sjaja neophodno je poliranje lakirane površine tj. brušenje lakirane površine vrlo sitnim brusnim zrnima. U ovom radu ispitano je kako pojedine faze procesa poliranja utiču na hrapavost lakirane površine i stepen sjaja. Hrapavost lakirane površine izražena je parametrima: $R a ; R z$ i Rt; a sjaj lakirane površine je određen primenom dve geometrije merenja: $20^{\circ} i$ $60^{\circ}$. Utvrđeno je da kroz faze poliranja hrapavost lakirane površine opada, a stepen sjaja raste. Visoka vrednost koeficijenta determinacije $(R=0,984)$ pokazala je da postoji linearna zavisnost između parametra hrapavosti $R_{a}$ i sjaja lakirane površine (mereno pod uglom od $60^{\circ}$ ). Primena dve geometrije merenja $\left(20^{\circ}\right.$ i $\left.60^{\circ}\right)$ je potvrdila potrebu primene geometrije od $20^{\circ}$ kada se određuje sjaj visoko sjajnih površina, jer standardna geometrija od $60^{\circ}$ ne obezbeđuje sagledavanje malih razlika u stepenu sjaja koje nastaju kao posledica poliranja.

Ključne reči: premaz, poliranje, površinska hrapavost, visoki sjaj.

Naučni rad

Rad primljen: 24. 06. 2015.

Rad prihvaćen: 23. 08. 2015.

Rad je dostupan na sajtu: www.idk.org.rs/casopis 